\title{
Study on Quantitative Analysis of Wear Debris for Surface Modification Layers Ti(C,N) with Piston Ring on Diesel Engine Oil
}

Nag-Jung Choi $^{\dagger} \cdot$ Suk-Bum Youn $^{1} \cdot$ Min-Soo Kim $^{1}$

(Received April 30, 2009 ; Revised November 5, 2009 ; Accepted November 5, 2009)

\begin{abstract}
During contact between surfaces, there is wear and the generation of wear. The particles contained in the lubricating oil carry detailed and important monitoring information about the condition of the machine. Therefore, this paper was undertaken for the Ferrography system of wear debris generated from a lubricated moving machine surface. The lubricating wear test was performed under different experimental conditions using the Falex wear test of the Pin and V-Block types by $\mathrm{Ti}(\mathrm{C}, \mathrm{N})$ coated. It was shown from the test results that wear particle concentration(WPC), wear severity index(Is) and size distribution have come out all higher with increases in sliding friction time. With the Ferrogram thin leaf wear debris as well as ball and plate type wear particles were observed.
\end{abstract}

Key words: Wear, Lubrication, Engine oil, Surface modifiation, Quantitative analysis, Wear debris

\section{Introduction}

Wear debris, which is caused by interactions with the lubricant, happens inevitably and the shape of wear debris is directly related to the lubricous face and its damage. In other words, this lubricous surface is accompanied by various lubrication problems according to its quality, form of contact, lubricous particles, and it is complicated by and directly related to the lubricous surface[1]-[4]. For this reason, in the case of a defect in a particular part, heat is produced and this can cause distortion in sounds or vibration. In addition, wear debris out of the defective or heat-derived elements will be represented in lubricating oil or discharge sludge and discovering disorders by examining them is an important theme for the diagnosis and maintenance of machinery[5]-[7].

Basic understanding about lubricating tools or damage is quite important, as it is the same in new technologies needing basic fields. Thus, a basic understanding about damage on the lubricating tool has been learned by analyzing the same grade in the lubricating oil, water, polluting material, etc[8]-[10].

But despite full recognition in the fact that observation and interpretation of lubricating particles provides much information on interpreting damage recognition, diagnosis and lubricating tool, treatment on the lubricating particles is in

\footnotetext{
† Corresponding Author (Division of Mechanical Design Engineering, Chonbuk National University E-mail : njchoi@chonbuk.ac.kr, Tel : 063)270-4765)

1 Division of Mechanical Design Engineering, Chonbuk National University
} 
limited and isn't utilized effectively [11]-[12].

Up until now, the Ferrography Method that evaluates the size, shape, color and quality of alien substance and the SOAP (Spectrometric Oil Analysis Program) method that judges from analysis on metal element are being used representatively.

The Ferrography method can distinguish magnetic materials like metal, cast iron and non-magnetic materials like sand, sludge and copper, so it will be used for analysis both on the quantity and quality of WPC(Wear Particle Concentration), size and shape of wear particles by using the Ferrography system for interpretation on wear debris from the lubricating surface.

\section{Experiment}

The experimental device used for this research was Falex defacement machinery and is shown in Figure 1.

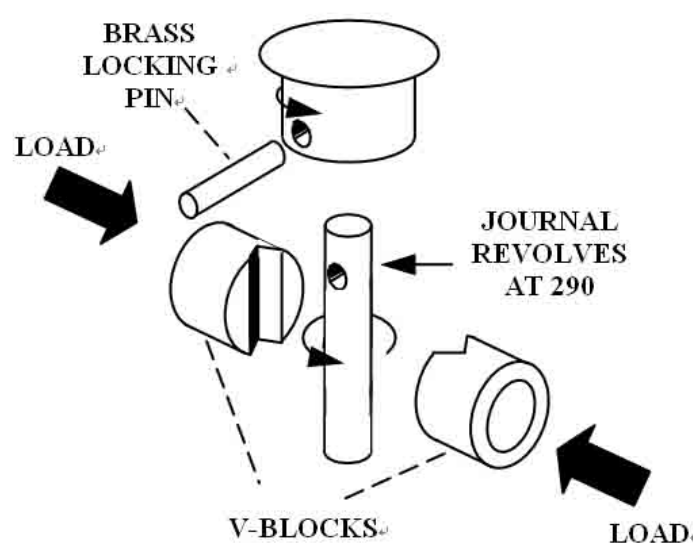

Figure 1: Exploded view of V-blocks and journal arrangement

The pin experiment used AISI 3135 steel of $6.35 \mathrm{~mm}$ width, and the V-Block experiment used AISI 4130 steel, with $\operatorname{Ti}(\mathrm{C}, \mathrm{N})$ was attached.

The lubricating oil used was diesel engine oil SAE\#30.

Table 1: Micro-structural and mechanical properties of $\mathrm{Ti}(\mathrm{C}, \mathrm{N})$

\begin{tabular}{|c|c|}
\hline Properties & $\operatorname{Ti}(\mathrm{C}, \mathrm{N})$ \\
\hline Melting Point, $\left[{ }^{\circ} \mathrm{C}\right]$ & 3300 \\
\hline Density, $\left[\mathrm{g} / \mathrm{m}^{3}\right]$ & 5.78 \\
\hline Hardness Hv, 〔 $\left[\mathrm{kg} / \mathrm{mm}^{2}\right\rceil$ & 4000 \\
\hline $\begin{array}{c}\text { Friction Coefficient with } \\
\text { steel }\end{array}$ & 0.55 \\
\hline (dry condition) & \\
\hline Reaction Material & $\mathrm{CH}_{4}, \mathrm{~N}_{2}$ \\
\hline Thermal Expansion & \\
\hline $\begin{array}{c}\text { Coefficient } \\
\left(10^{-6} /{ }^{\circ} \mathrm{C}\right)\end{array}$ & 9.82 \\
\hline
\end{tabular}

Figure 2 shows a rough picture of the Ferrography system used to get information regarding shape, size, and numbers of particles. Using this we judged whether is normal or abnormal; the representative deface meant particle is followed by references.

Incorrect conditions at the time of defacement, like weight and sliding distance followings information such as shape and size of defacement.

We unified the sliding speed at $9.5 \mathrm{~mm} / \mathrm{s}$, and verified the weight at $3.3 \mathrm{kN}$ and $5.5 \mathrm{kN}$, and selected diesel engine oil SAE \#30 as an experimental oil.

We opted for one that was used 20hours in standards for experimental oil by sliding time. We also used Diluents for the sample, preparing 6 oil samples from $5.5 \mathrm{kN}$ and 4 oil samples from $3.3 \mathrm{kN}$, which were mixed at different rates. 


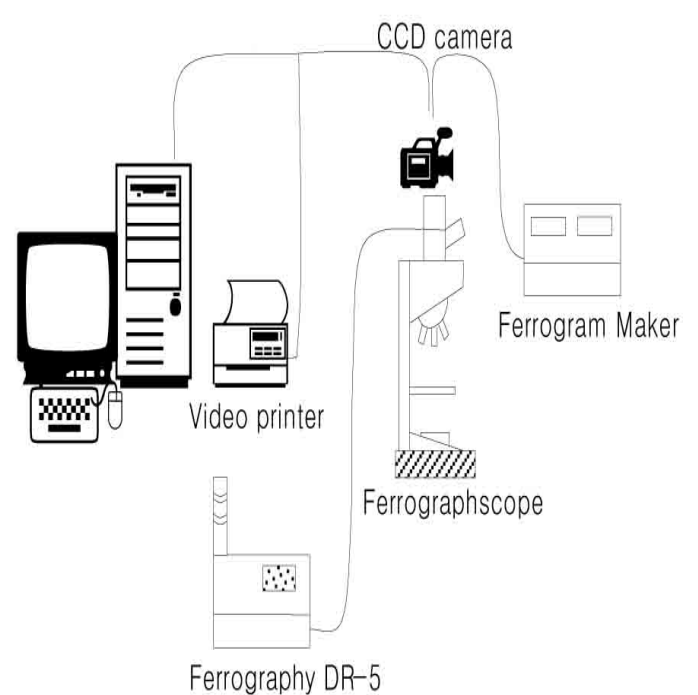

Figure 2: Schematic diagram of Ferrography analysis system

Repetitions of evolution in Quantize analysis were quite sensitive in detection level but it was within $3 \%$ under the tuned condition on the optima.

Conditions in Quantimet 720

Magnification : object lens $25 \mathrm{x}$, condenser $6.3 \mathrm{x}$

Lighting : reflected light source

Detection : lighter than background

1 picture point is equivalent to $0.65 \mu \mathrm{m}$

Ferrogram slide details are followed and the last numbers indicate the dilution ratios.

Slide Nos.

$$
\begin{aligned}
& \mathrm{W}=3.3-5 \\
& \mathrm{~W}=3.3-10 \\
& \mathrm{~W}=3.3-15 \\
& \mathrm{~W}=3.3-20
\end{aligned}
$$

$$
\begin{aligned}
\text { Slide Nos. } \mathrm{W} & =5.5-0 \\
\mathrm{~W} & =5.5-5 \\
\mathrm{~W} & =5.5-10 \\
\mathrm{~W} & =5.5-15 \\
\mathrm{~W} & =5.5-20 \\
\mathrm{~W} & =5.5-30
\end{aligned}
$$

\section{Result and discussion}

\subsection{Analysis of fixed quantity by dilution}

The results, attained by analysis of fixed quantity, are shown in Table 2 and Figure 3.

Table 2 represents the initial evaluation of intercept, perimeter, area, and influences of dilution. These variables were $2 \sim 3$ times higher at the high weight $(5.5 \mathrm{kN})$, but it increased 5 times in the case of lower weight. In contrast, these variables diminished in inverse proportion to the increasing dilution rate.

Sample dilution and total sum of the particles' change are shown in Figure 3 for this standard.

The total sum of particles represent the sums of particles $\leq l p p$ and the sums of particles $>l p p$.

Table 2: Initial measurements evaluation for a dilution effect

\begin{tabular}{c|c|c|c|c|c}
\hline & $\begin{array}{c}\text { Sample } \\
\text { dilution }\end{array}$ & $\begin{array}{c}\text { Total No. } \\
\text { of } \\
\text { particles, } \\
(>0.5 \mu \mathrm{m})\end{array}$ & $\begin{array}{c}\text { Area } \\
\text { covered } \\
(\mathrm{A}) \\
(\mathrm{pp})\end{array}$ & $\begin{array}{c}\text { Intercept } \\
(\mathrm{I}) \\
(\mathrm{pp})\end{array}$ & $\begin{array}{c}\text { Perimeter } \\
(\mathrm{P}) \\
(\mathrm{pp})\end{array}$ \\
\hline 3.3 & 5 & 368 & 2,327 & 674 & 3,208 \\
{$[\mathrm{kN}]$} & 10 & 172 & 1,418 & 278 & 1,033 \\
& 15 & 120 & 855 & 220 & 524 \\
& 20 & 52 & 278 & 96 & 475 \\
\hline & 0 & 1047 & 5,423 & 2,256 & 8,520 \\
5.5 & 5 & 528 & 4,878 & 1,645 & 5,254 \\
{$[\mathrm{kN}]$} & 10 & 346 & 1,423 & 1,002 & 679 \\
& 15 & 260 & 1,146 & 896 & 1,721 \\
& 20 & 203 & 1,087 & 821 & 835 \\
& 30 & 111 & 696 & 449 & 728 \\
\hline
\end{tabular}




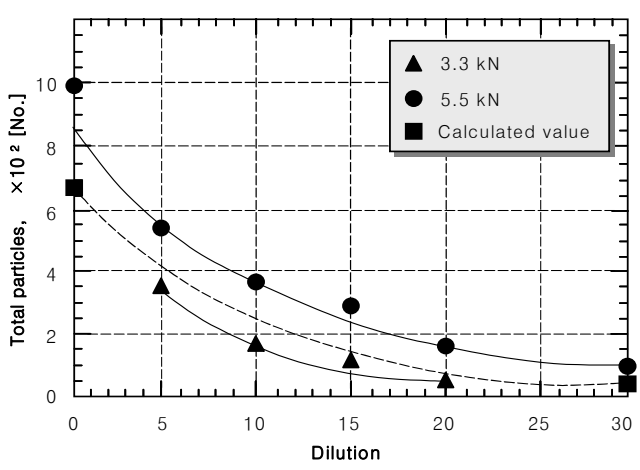

Figure 3: Total particle count vs dilution oil samples from Falex test machine(SAE \#30)

The distribution of the particles' size decreases functionally with the increase of dilution samples in Figure 3, which has a particular particle bandwidth.

These changes in the distribution of the size of particles affect the interpretation of the defacement situation.

The cuts and lengths are shown in Table 4 for the influence of dilutions on the area under the condition of $3.3 \mathrm{kN}$ and $5.5 \mathrm{kN}$.

When deciding general function of the dilution sample, it can be expressed in the form of Hyper exponential function, according to the results of Figure 3 . Equation(1) can be sectored by algebra variation as the following.

$$
\mathrm{y}=a \exp (-b \mathrm{x})
$$

Where, $\mathrm{y}=$ numbers of particles. Particular variation(area, cut, length) and $\mathrm{x}=$ grade of dilution sample, and $\mathrm{a}, \mathrm{b}=$ invariable number calculated from experimental evaluation.

$\ln \mathrm{y}=-b \mathrm{x}+\ln a$

Where, $\mathrm{b}=$ slope of function and $\mathrm{a}=$ particle value in a certain location by $\mathrm{x}$ dilution.

The results were sectored in equation(2), as shown in Figure 3, and are also shown in Figure 4 by minimum squaring and as a result, it links to an excellent related coefficient.
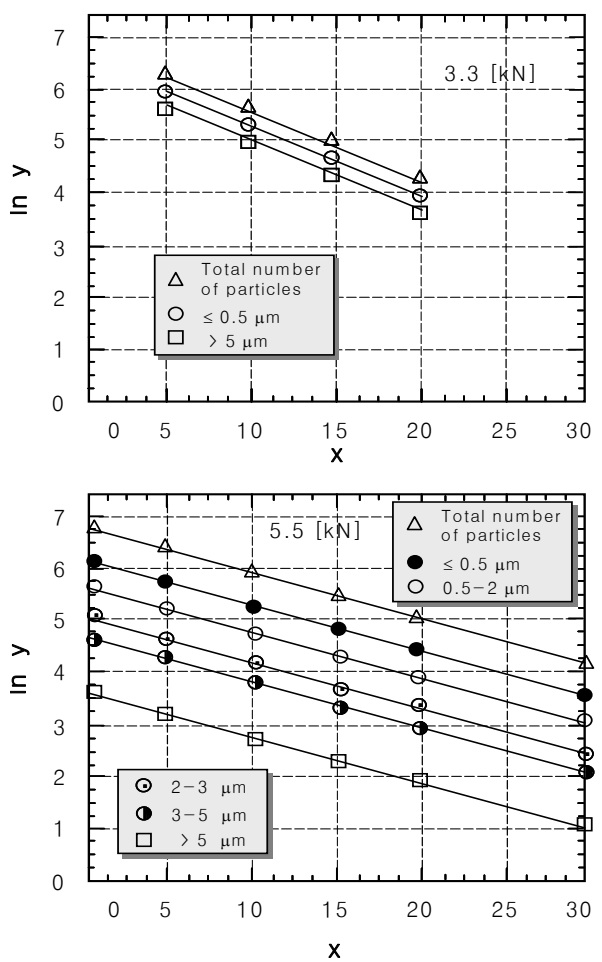

Figure 4: Exponential plots vs dilution(x) at weight $3.3[\mathrm{kN}]$ and $5.5[\mathrm{kN}]$

Though there is a remarkable decrease in the related coefficient, the slope value shows quite a slight difference than the value in $5.5 \mathrm{kN}$, and in that context, the changes in the slope on the different sizes are quite small. And this means thickness change of dilution sample does not affect particle distribution. It might be a result that accumulated particles exist relatively as dilution increases, as in Figure 4. 
In addition, it is quite difficult to effectively show very low particle distribution deposited from material estimates, which was used in the Ferrogram. So, the analysis method of the defacement particles in a lubricating system depends on the condition of delivery and is also dependent on the particles.

For these reasons, changes in the particles' size should be considered from the deferment form on the system.

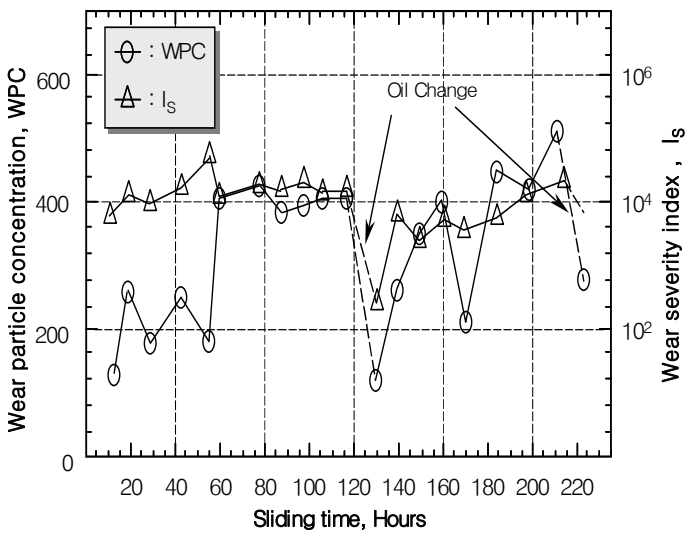

Figure 5: Relation of wear particle concentration and wear severity index in normal wear

\subsection{Analysis of defacement on the normal mode}

The polished, regularly picked sample ore is shown in Figure 5 from the result of calculating WPC by DR5 Ferrography. And except the tread in wear, we confirmed the fact that wear debris' amounts increases, with the increase of sliding hours. And we showed the numbers of particles of non-iron metal in Figure 6, which was observed by the Ferrogram at $50 \mathrm{~mm}$ in FMIII. The standards of the fixed quantity Ferrogram used in this case are ex-WPC, index of defacement (Is), and the numbers of defacement particles in non-iron metal, and WPC and Is in Fig 5 represents low values in 200 and $10^{2}$ just after oil exchange, but it shows increases both in WPC at 400 500 and Is at 104 106by heating lubricating oil.

So, the increase in WPC precedes the defacement index Is.

Figure 6 is the standard judging disorder in machine condition monitoring, it indicates the timing of oil exchange and also works against preceding disorders. Here we adopted the timing of oil exchange with the standard of $5 / 1 \mathrm{~m} \ell$ particles are in $10 \mu \mathrm{m}$, and fixed the disorder occurring at more than 10 particles. So particle numbers over $10 \mu \mathrm{m}$ were equal, unlike the results in the WPC and Is.

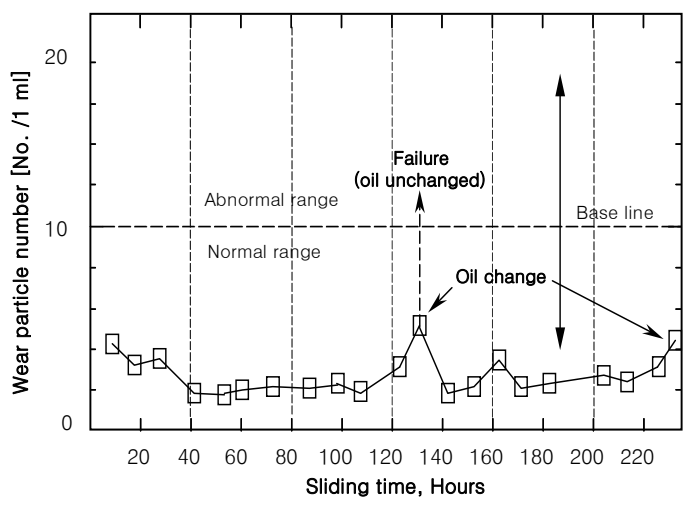

Figure 6: Relation of wear particle number for sliding time (for a $10 \mu \mathrm{m}$ over in nonferrous metals).

Figure 7 is the defacement picture of the sliding surface photographed by optical microscope. The size of wear debris is $2-3 \mu \mathrm{m}$ maximum, the form of the wear debris appeared simultaneously with the normal defacement particles and a globular shape defacement particle, and 
the colors coexisted with the white which came out of the surface layer brown. This shows it separated and melted with the increase in rubbing, and it appeared brown, its original color, by the time of polishing at the early stage. The metal damage derived from normal defacement mode affects other damage by melting the of titanium layer at the early stages of the disorder symptom.

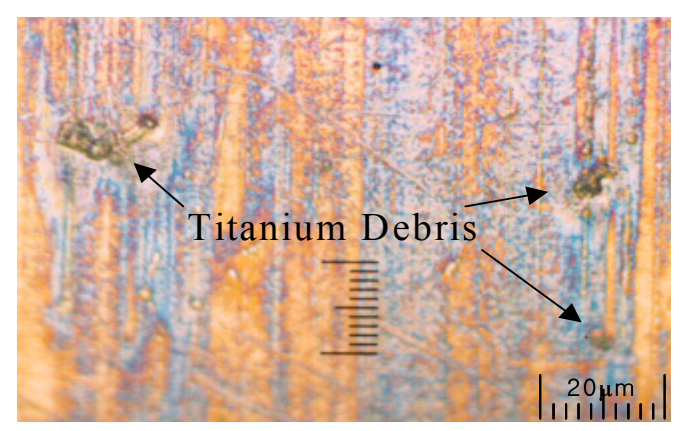

Figure 7: Photo. of wear debris in surface friction (normal wear mode range).

\subsection{Analysis of defacement at abnormal defacement mode}

Ferrography shows from the initial work of a machine to the defacement state in normal, and abnormal states that the fundamental premise of machine diagnosis is the distribution of the wear debris and the increase of the base line, previously determind, as the cause; this is also the conclusion of many scientists ${ }^{[12]}$.

Thus, under the condition of no exchange of lubricating oil, an abnormal state can happen from problems, such as seizure and the heating of lubricating oil.

We showed the results of fixed quantity Ferro- $^{-}$graphy in Figure 8 with the timed increases of defacement, and sliding surface in Figure 9.

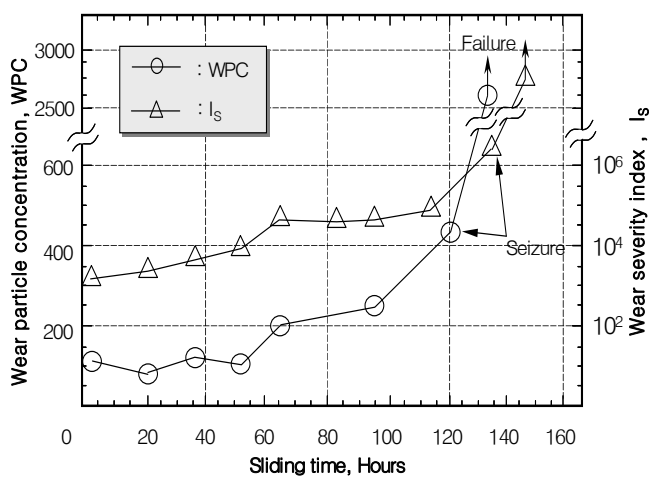

Figure 8: Relation of wear particle concentration and wear severity index in abnormal state wear.

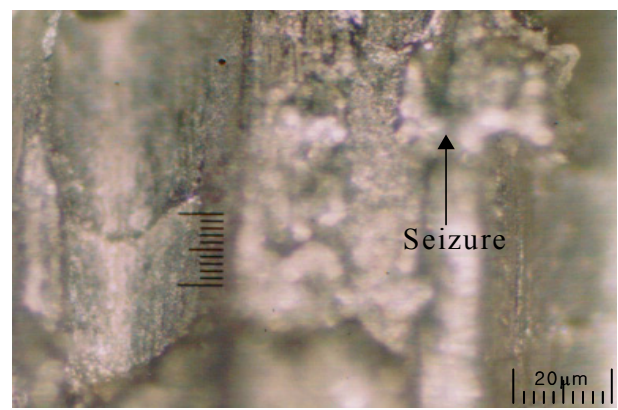

Figure 9: Photo. of seizure occurred in surface friction.

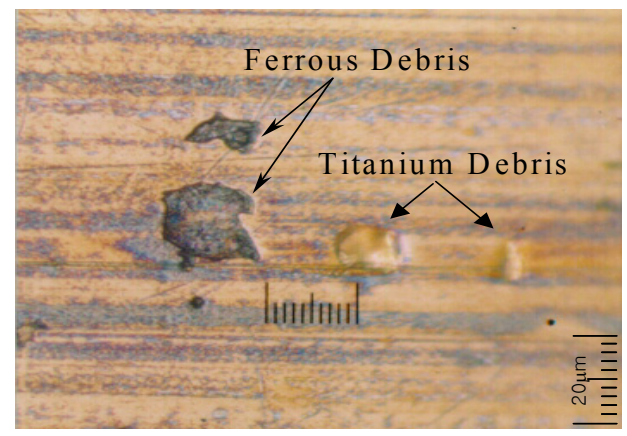

Figure 10: Photo. of wear debris in surface friction (abnormal wear mode range).

WPC and Is can cope with disorder symptoms and disorder occurrences in the 120-140 range of sliding hours, but what was not predictable is what is shown in Figure 10; in the sliding surface before 80 hours of sliding. WPC and Is just needs 
lubricating oil exchange because the result of Figure 5 is within general category. But we found that non-iron metal particles exist on a large scale with the result of observation in the Ferrogram.

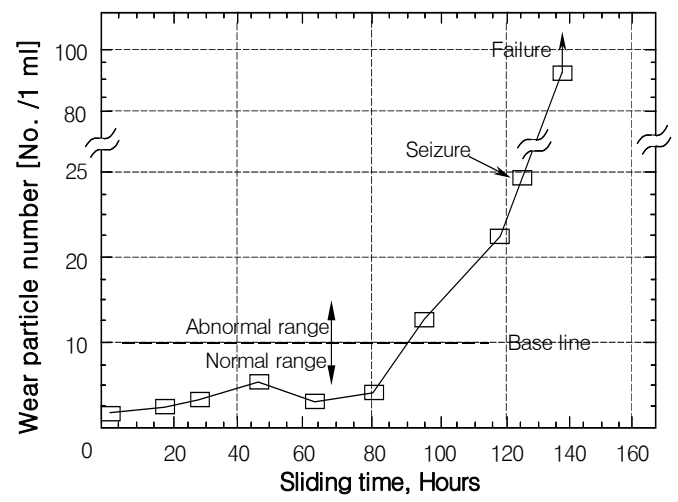

Figure 11: Relation of wear particle number for sliding time(for a $10 \mu \mathrm{m}$ over in nonferrous metals).

The wear debris' size varies from $5-20 \mu \mathrm{m}$, the forms of the wear debris were found to be cut normal wear debris and flat cut wear debris, and also the information on color was equal to the normal defacement mode by the time metal damage occurred from the surface damage. Just before the seizure happened, titanium particles more than $10 \mu \mathrm{m}$ increased and it directly affected the seizure, which is an abnormal symptom due to metal damage. In the case of metal damage on the lubricating surface, it is the standard of the disorder and its degree, being judged as the damage sign in the case of more than 10 particles observed in the Ferrogram. (Figure 6 and Figure 11)

In addition, metal damage can be fatal seizure damage when the titanium layer which consists of a metal layer is damaged to lower than $10 \mu \mathrm{m}$ particle.

\section{Conclusion}

This paper was undertaken for the Ferrography system of wear debris generated from a lubricated moving machine surface. The following conclusion were obtained from the test results above.

(1) Particle evaluation in fixed quantity analysis shows 25\% value around when defacement particles accumulated to more than 500 in a certain spot, and it is the influence of light spreading.

(2) Titanium particles in the surface layer appeared in the early stage, WPC and Is values almost doubled with the increase of sliding, and metal particles more than $10 \mu$ mappeared, which became the cause of the seizure.

(3) The form of the defacement coexists with cut normal defacement particles and globular shapes in the early stage, but flat-cut defacement particles were found with the seizure phenomenon and color information of the defacement particle showed as brown and black with the increase of rubbing hours.

(4) The heating of lubricating oil by the increase in sliding rubbing hours became the cause of WPC and Is increase, the bigger defacement particles easily oxidized and the disorder symptom could be foreseeable according to the increase of defacement formation and changes in color.

\section{References}

[1] W.W. Sefect and V.C. Westcott, "A Method for the study of wear particles in Lubricating Oil", Wear, vol. 21, pp. 27-42, 1972.

[2] A.D.H. Thomas, T. Davies and A. R. 
Luxmoore. "Computer image analysis for identification of wear particles", Wear, vol.142, pp. 213-226, 1991.

[3] T.B. Kirr, D. Panzera, R.V. Anamalay and Z.L. $\mathrm{Xu}$, "Computer image analysis of wear debris for machine Conkition Monitoring and fault Diagnosis", Wear, vol. 181, pp. 717-722, 1995.

[4] N.J. Choi and S.B. Youn, "A study on the tribological characteristics of automobile gear oil with addition of compound additives", Journal of KOSME, vol. 32, no. 4, pp. 557-562, 2008.

[5] Masaaki Shibata, "Tribological characteristics and diagnosis of deteriorated lubricating oil", Tribologist, vol. 39, no.7, pp. 559-565, 1994.

[6] Motofumi Kurahashi, "Tribology management and life estimation of steel making plants", Tribologist, vol. 39, no.7, pp. 596-599, 1994.

[7] R.C. Moore, Perkins and D. Michael. etc, "Wear particle atlas", Manual, Predict Co, pp. 50-153, 1995.

[8] H. Gad, G. C. Barber and H. Chu, "Friction characteristics of a paperbased friction materials", Int. J. Automotive Technoloy, vol. 3, no. 4, pp. 171-176, 2002.

[9] S. Jang and J. Cho, "Effects of skirt profiles on the piston secondary movements by the lubrication behaviors", Int. J. Automotive Technoloy, vol. 5, No. 1, pp. 23-31, 2004.

[10] K. Chun and M. Sunwoo, "Wheel slip control with moving sliding surface for traction control system", Int. J. Automotive Technoloy, vol. 5, no. 2, pp. 123-133, 2004.

[11] Y. H. Cho, S. M. Oh and B. G. Rhee,
"A study on the wear characteridtics of ceramics coating with PVD", Transactions of the Korean Society of Mechanical Engineers A, vol. 22, no. 7, pp. 1129-1236, 1998.

[12] S. M. Oh, B.G. Rhee and B. S. Jeong, "Wear behaviors of ceramics TiN, TiC and TiCN with arc ion plating”, Int. J. KSME, vol. 17, no.12, pp. 1904-1911, 2003.

\section{Author Profile}

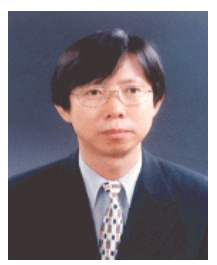

Nag-Jung Choi

Ph.D. degree were from Dept. of Mechanical Engineering of Hanyang University in 1995. Present, Professor of Division of Mechanical Design Engineering at Chonbuk National University in jeonju, Korea.

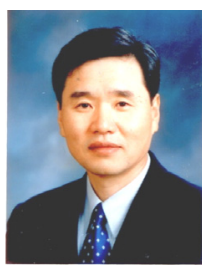

\section{Suk-Bum Youn}

Received B.S. degree from Korea Maritime University in 1974.

M.S. and Ph.D. degrees were from Dankuk University in 1882 and 1988.

Present, Professor of Division of Mechanical Design Engineering at Chonbuk National University in jeonju, Korea.

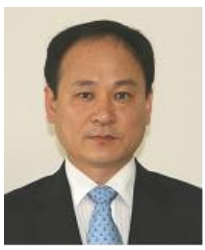

\section{Min-Soo Kim}

Ph.D. degree were from Dept. of Mechanical Engineering Jeonbuk National Univ. in 1993.

Present, Professor of Division of Mechanical Design Engineering at Chonbuk National University in jeonju, Korea. 